\title{
Research on the Prevention and Control of Legal Risks in Internet Financial Innovation
}

\author{
Chengyong $\mathrm{Liu}^{1, \mathrm{a}^{*}}$ and Cheng Chen ${ }^{2, \mathrm{~b}}$ \\ ${ }^{1}$ Beijing Institute of Technology, Zhuhai, Guangdong, 519088 China \\ ${ }^{2}$ National Taiwan University, Taipei 10617, Taiwan, China \\ a liucy13@126.com, ${ }^{\mathrm{b}}$ legalcici@gmail.com
}

Keywords: Internet Finance; Innovation; Legal Risk Prevention; Supervision and Management

\begin{abstract}
With the innovation and entrepreneurship proposed, the development of information technology, the Internet is widely used in various fields, and the world has gradually entered a new era of the Internet. The Internet has promoted the socio-economic structure of human beings, and the Internet has exerted a tremendous influence on the social transformation and development model. Internet gold was born under such a background of great development and great changes. It has rapidly developed into a new financial model in the global context. Different from the traditional financial industry, Internet finance is a "new species" resulting from the complementarity and combination of two different characteristics of the Internet technology and finance industries. Coupled with the rapid development in recent years, it has rushed out of the scope of effective control of the traditional financial industry. It has many loopholes and risks in legal guidance and regulation. From the perspective of innovative legal risk prevention, this paper comprehensively analyzes the main models of China's Internet finance and the existing legal risks. In combination with advanced foreign regulatory experience, this paper makes a comparatively in-depth analysis and discussion of China's current Internet financial innovation legal risk prevention. From the actual combination of supervision provides some of their own ideas and suggestions.
\end{abstract}

\section{Introduction}

Internet finance is an emerging financial industry that has developed based on internet technology. Compared with the traditional financial industry, the disadvantages of Internet finance are also extremely prominent, and the risks and challenges it faces are also difficult to control, especially in the prevention of legal risks in Internet finance. Due to the lagging, lacking and limitations of the law itself, the prevention of Internet financial legal risks has become a major problem that restricts the health and sustainable development of Internet finance. From the perspective of government regulatory agencies, the healthy development of Internet finance has a bearing on the stability and long-term development of the entire social economy. From the perspective of the Internet finance industry and enterprises, the healthy development of Internet finance can promote the further development of the entire financial industry. Promote the growth of enterprises themselves and maximize profitability. From the perspective of Internet finance investors, a good internet financial investment environment can obtain investment returns and achieve investment objectives on the premise of reducing their own investment risks. The more reasonable the measures for the supervision and prevention of Internet financial legal risks, the more effective the final results achieved. Therefore, this paper tries to make in-depth and detailed investigations on the difficult issues of internet finance related to the innovation risk prevention aspect of the Internet, and puts forward suggestions for improving the legal aspects.

\section{The Main Mode of Internet Finance}

As a new thing, Internet finance is still in the process of continuous development and improvement. It is still too early to draw conclusions on it. For an area that is still constantly diversifying and combining, we combine the current development of Internet finance in the physical industry and 
combine its future development trends. The major modes of Internet finance are the following.

\section{P2P network loan}

Peer-to-Peer lending (P2P) refers to point-to-point credit. $\mathrm{P} 2 \mathrm{P}$ online lending refers to borrowing and lending of funds by third-party Internet platforms. Lenders look for willingness and ability to lend to groups on the Internet platform. They take credit risks with lenders and help borrowers choose after full comparison. Interest rates are higher, and more lenders benefit from lending money.

\section{Crowdfunding}

Crowdfunding, also known as public fundraising, refers to obtaining financial assistance by showing your project to investors. Crowdfunding is the use of the fast-propagating nature of Internet finance to allow entrepreneurs, individuals, or public institutions with entrepreneurial intentions to publish and display their own ideas and projects through the Internet platform. This will provide investors with funds for their interest. Crowdfunding organizations need to obtain relevant audits before they can carry out project promotion and popularization.

\section{Network Virtual Currency}

Refers to an unreal currency. It is based on the Internet Information Network, using computer technology and communication technology as a means to digitally realize the online equivalent of circulation and payment. Bitcoin is one of the representatives. Its characteristic is that it does not require physical exchange, but it is registered as a symbol. It is generally only distributed on the Internet and does not have the functional attributes of general equivalents in real life. The emergence of Bitcoin reflects the essence of Internet finance is the currency of the Internet virtualization.

\section{Internet Insurance}

In simple terms, it is a way to carry out insurance marketing online by taking advantage of the convenience of Internet technology. Internet insurance refers to the market economy that conducts insurance business promotion and marketing on the Internet, using Internet technology and e-commerce as the medium. Compared with traditional insurance products and sales models, customers can compare product deadlines, insurance reputations, and insurance premiums of multiple insurance companies online to clearly identify product features, costs, and risk analysis, and then freely choose their own conditions and requirements. In order to minimize the risk, obtain insurance income, and then protect their own legitimate rights and interests.

\section{Overview of Internet Financial Legal Risk}

The healthy development of Internet finance requires the support of internet technology, the need for the prevention and control of risk prevention technology, and the need for legal protection; it requires both a soft law culture and a hard law structure; it requires both accurate grasp of financial risks and strict compliance with by law. Therefore, the emergence of Internet financial legal risk has its inevitability. On the one hand, it is determined by the inherent limitations of law's lag, dependence, and uncertainty; on the other hand, it is the nature and characteristics of Internet finance. definite. Internet finance is a new industry resulting from the combination of the Internet and the financial industry. Compared with the traditional financial industry, the emergence of Internet finance lacks rigor and standardization, coupled with its rapid development, and is destined to bring certainty to the current financial market. The degree of shock and pressure. At the same time, due to the huge cultural differences between the two, various types of Internet financial products have legal risks in varying degrees, which has led to the confusing development of Internet finance. The so-called legal risks of internet finance mainly refer to the changes in the environment of external laws and regulations of internet financial institutions and investors, or the fact that they do not have legal basis and do not effectively exercise their rights and perform obligations in accordance with the provisions of the contract, resulting in negative results. Legal consequences of various types of risks. 


\section{The Risk of Internet finance}

\section{Legal Risks of Business Information Disclosure}

For the P2P online loan platform, in order to obtain symmetry of information and gain the trust of investors, various information of the borrower needs to be published on the network, and this information belongs to the core business information for the network platform. When competing with other network platforms or competing with customers, it is easy for opponents to obtain, thus losing the initiative and advantages in competition, and leading to the emergence of a series of legal issues.

\section{Legal Risks of Privacy Inf ringement}

The main subject of this type of risk is the users of Internet finance. For example, in August 2014, some people complained that their Alipay personal information was posted on the Internet inexplicably. The relevant information included such information as name, home address, contact information, and amount of money. After investigation, Alipay explained that it has already protected the relevant information with security and encryption. Under normal circumstances, there will be no leakage of privacy and secrets. Such an accident may be due to the user's own use of Alipay. Not due to precautions.

\section{The legal risks between the lending entities}

This mainly refers to the legal risks caused by excessively high lending rates. First of all, as a new type of financial management model, for lenders, lending funds through internet platforms is to obtain higher investment returns than bank deposits, but at the same time it is bound to take higher profits than bank deposits. Risk hidden dangers. The unrecoverable cost, the illegality of the investment platform or the "walk" can all cause huge losses; for the borrower, it lacks funds itself, and the high interest payment makes it more difficult to repay, so it may face legal liability at any time. For the lending platform, high-risk brings high profits. For each platform to compete for the customer base, it will inevitably drive up the revenue, making the high-interest agreement stipulated by the illegal national laws and regulations, and at the same time, once the borrower cannot pay, the entire There will be problems in the links, and companies themselves will inevitably face serious legal risks. In addition, the adjustment of national policies and the improvement of laws and regulations will also bring challenges to the investment platform.

\section{Legal Risks of Internet Direct Selling Funds}

The Internet economy is a typical eyeball economy that stimulates users' eyeballs as an important marketing tool. Since the Internet organizations entered the financial industry, they have not carried out their business operations in accordance with the requirements and provisions of the law in many respects, and have resorted to legal blanks. For example, there are fund projects launched by Internet organizations and they have been described as zero-risk in publicity. This is clearly contrary to relevant laws and regulations in China. Therefore, such products will inevitably be illegal, and there is a risk that the benefits due to contract invalidation will not be realized.

\section{Research on the Prevention of Legal Risks in Internet Financial Innovation}

\section{Implementation of a Business License System for Internet Financial Companies}

To promote the supervision of Internet finance, and to coordinate and cooperate with various regulatory agencies, the regulatory authority can implement a business license system for the access of Internet finance companies, and establish a mandatory information disclosure system similar to that of the securities market to safeguard consumers' Right to know and strengthen social supervision of internet financial institutions. The current regulatory authority can first issue business licenses to some Internet companies with a high level of development and a high level in the industry. They must strictly control their operation methods and capital flows to prevent the further penetration of legal risks, especially the P2P financing platform and the In the field of tripartite payment platforms, and successively liberalizing access requirements in the Internet finance sector, the entry threshold has been lowered, and the entire Internet finance industry has developed in a healthy and stable manner. 


\section{Establishing a Credit System for Internet Financial Enterprises}

Establish a credit system for internet finance companies, establish a credit database for relevant transaction data of various trading platforms, and require internet financial institutions to cooperate with banks to ensure third-party custody of funds. The establishment of a credit information system and database will help standardize the behavior of Internet finance companies and guide them to engage in normal trading activities within the framework of laws and regulations. At the same time, they provide conditions and basis for the disclosure and disclosure of information and facilitate the disclosure of Internet companies. Transparent, to ensure that users freely choose and know the situation.

\section{Formulate a Reasonable and Effective Emergency Plan}

As the first person responsible for preventing and resolving legal risks, internet finance companies have obligations and conditions to bear corresponding responsibilities. The occurrence of legal risks in Internet financial institutions is sudden and unpredictable, so it is difficult to fully prepare for prevention in advance. When legal risks occur, internet financial institutions should promptly refute or review the situation, seek assistance from relevant regulatory agencies and local governments, and actively request assistance from interbank financial institutions to avoid irreparable loss caused by the exaggeration of risks. At the same time, it is necessary to do a good job of appeasing investor sentiment, explain the relevant conditions in a timely manner, stabilize the online funds and psychological expectations of customers, and strive to solve problems quickly.

\section{Strengthen the Self-Regulatory Role of the Industry}

The healthy development of internet finance can not be separated from the guidance and supervision of the government's supervisory departments, but at the same time it also requires the industry to strengthen self-discipline. In the Internet finance industry, although various companies have different business forms, development stages, and asset sizes, there are bound to be various business contacts and related aspects that can be used for reference. Therefore, all Internet finance enterprises should establish a unified industry association, formulate industry standards, jointly implement national guidelines and policies and industry standards, strengthen self-regulation and compliance construction, avoid vicious competition, waste resources, and damage the interests of investors. By strengthening the cooperation among the Internet finance industry associations, the Internet industry associations, and the financial industry associations, they will work together to maintain the order of competition in the Internet industry, avoid vicious competition, and damage the public interest.

\section{Conclusion}

Internet finance combines the dual factors of the Internet and finance. Its risk is dual, affected not only by financial risks but also by Internet risks. Internet financial risks can be divided into two categories. One is conventional risks that are consistent with traditional financial fields. There are market risks, credit risks, operational risks, liquidity risks, and reputation risks. These risks are due to the penetration of Internet financial characteristics. Causes, forms of manifestation, harm levels, etc. are different from traditional financial risks. Based on the innovation of legal risks and based on the relevant problems in the current development of China's Internet finance, this paper empirically studies the factors influencing the risks of Internet financial institutions and the impact on users' use of the Internet from the perspective of Internet financial institutions and Internet financial users. In this way, we propose targeted prevention mechanisms for internet financial risks.

\section{Acknowledgement}

The paper is a periodical achievement of the 2018 school-supported scientific research program A Study on Liability Theories about Insider Trading of Financial Derivatives of Beijing Institute of Technology, Zhuhai (XK-2018-19). 


\section{References}

[1] Arvanites D A, Glasgow J M, Klingler J W, et al. Innovation in entrepreneurship education[J]. Journal of Entrepreneurship Education, 2006, 9:29-44.

[2] Busch T, Stinchfield B T T, Wood M S S. Rethinking Sustainability, Innovation, and Financial Performance[M]// Cross-Sector Leadership for the Green Economy. Palgrave Macmillan US, 2011.

[3] Home O, Affairs C. Improving Corporate Governance in India - Related Party Transactions and Minority Shareholder Protection[J]. 2014.

[4] Hechavarría D M, Welter C. Opportunity Types, Social Entrepreneurship and Innovation Evidence from the Panel Study of Entrepreneurial Dynamics[J]. International Journal of Entrepreneurship \& Innovation, 2015, 16(4):1.

[5] Fairlie R W, Lofstrom M. Chapter 17-Immigration and Entrepreneurship[J]. Handbook of the Economics of International Migration, 2015, 1:877-911.

[6] Li, Z., \& Qiu, Y. (2016). Coupling of regional financial agglomeration and innovation and entrepreneurship_ an empirical analysis based on panel var. Academic Exchange.

[7] Kang G D, Zhang Y L, Zhou Q P. Positive Integration to "Internet+", Assistance to Innovation and Entrepreneurship Talents Cultivation —-Take Teaching Reform of Social Network of Jishou University as an Example[J]. Modern Educational Technology, 2016.

[8] Hueske A K, Guenther E. What hampers innovation? External stakeholders, the organization, groups and individuals: a systematic review of empirical barrier research[J]. Management Review Quarterly, 2015, 65(2):113-148.

[9] Lopez-Valeiras E, Gonzalez-Sanchez M B, Gomez-Conde J. The effects of the interactive use of management control systems on process and organizational innovation[J]. Review of Managerial Science, 2016, 10(3):487-510.

[10] PAN Ye, School of Marxism, Southwest University. The Implications of President Xi's Views of Innovation and Entrepreneurship for Contemporary Youths' Innovation and Entrepreneurship[J]. Journal of Guangdong Youth Vocational College, 2016.

[11] ZHANG Guo-liang. Study on Approach of Innovation and Entrepreneurship for Local College Students in the Context of Transition and Development[J]. Journal of Xi'an University(Social Sciences Edition), 2017.

[12] Li, Gao. "Community Bank,Relationship Lending and Financial Support to Entrepreneurship and Innovation." Finance \& Economics of Xinjiang(2017).

[13] Zhan Y, Xu L, Business S O, et al. Financial Inclusion under "Internet Plus" and Household Entrepreneurial Decisions[J]. Journal of Finance \& Economics, 2017.

[14] Shi-Bo X U, Zhang L, Chen W. Analysis on Development of Crowdfunding Based on Innovation and Entrepreneurship[J]. Global Science Technology \& Economy Outlook, 2017. 